\title{
The Eighth Sustainable Development Goal considering the economic system and its contradictions - A Critique
}

\author{
José António de Sousa Pinho \\ Universidade NOVA de Lisboa - FCSH \\ zetopinho999@gmail.com
}

\begin{abstract}
This article focuses on the eighth Sustainable Development Goal (SDG) for the global community, analysing its objectives and recommendations that are to be achieved by 2030 in the sectors of economic growth and employment. It is a critique of the SDG chosen, in light of the current economic system and its contradictions, taking into account the new factors of the decade, such as technology and the environmental crisis. Economic growth was present in every economic analysis in the past decade, but should it be the focus of the next? The current environmental concerns have forced the global community to rethink the way we look at economic growth and the system in general. The article will also explore the contradictions in employment and work while attempting to explain the problems of this sector. A special attention will be given to profit and the way it prevents the creation of decent jobs. The new possibilities of the green economy and the technological progress will be taken into account and developed. It will finish with a reflection on the economic system in general and the SDGs, while also proposing a solution to the problems of the next decades concerning the economic and employment sector.
\end{abstract}

Keywords: Sustainable Development Goals no. 8, economic system, economic growth, environment, employment

\section{Introduction}

The Sustainable Development Goals (SDGs) is a set of goals proposed by the United Nations for mankind to achieve before 2030. These goals cover many different sectors and areas of society and present a general overview of the problems with those areas before indicating the goals themselves.

This paper will focus on the $8^{\text {th }}$ Sustainable Development Goal: "Promote sustained, inclusive and sustainable economic growth, full and productive employment and decent work for all”. It will begin with a deconstruction of the SDG, analysing its components. Firstly, a closer look at economic growth and its contradictions, and secondly a closer look at work and the problems attached. The author will then use this first analysis to elaborate a critique of the system in broader terms, always attempting to direct it through the SDGs. 
This critic of the system will lead to a critic of the SDGs in general and present different perspectives on them, connecting their problems with those of the system where the SDGs themselves are inserted. Finally, the paper will finish with a short consideration of potential solutions and alternatives.

In a time of economic and social instability, the relation between the SDGs and the system they are inserted in have become increasingly relevant. Other factors characteristic of the $21^{\text {st }}$ century like increasing automation and computerization and environmental factors increase the importance of the topic at hand.

This paper is meant as a reflection of the global scale in which the SDGs are thought to affect, and the way that the system interferes or even allows them to be successful.

\section{What is Economic Growth?}

Historically, due to the lack of accurate measurements, economic growth was a hard concept to grasp. As the records began to rise, and the stock markets began to flourish, economic growth became extremely important, however the problem remained. There are multiple factors that can determine the growth of a specific economy, and some of those factors cannot be measured. A few classical examples of the overlapping factors of economic growth are the physical environment of the economy, the institutional patterns and the way in which they are applied in such society, or even technology in a very broad and general sense. (Schumpeter 1947, 1-9) This predicament means that a precise definition of economic growth is hard to come by. Instead, multiple definitions are acceptable and have ample research to back them up.

As stated by Schumpeter, it becomes important for any investigator or academic to define precisely what is meant by economic growth. A certain investigator may prefer to focus on economic growth per capita or focus instead on total output of goods or services (Schumpeter 1947, 2), depending on the purpose of the investigation.

Therefore, it becomes necessary to define economic growth for this specific purpose. As it is not meant as a thorough economic analysis on economic growth, its definition is rather simplistic one, since it is more important to understand the concept of economic growth in a general manner than to acquire a specific and profound knowledge about the intricate functioning of economic growth. For this paper, economic growth will generally refer to the total GDP growth of a specific country as the criteria for economic growth or contraction. However, since there are multiple economies that used different currencies and values, it will be necessary for us to use the Purchasing Power Parity indicator (PPP) in order to compare them when necessary. The PPP basically compares prices on common goods between countries to compare their purchasing power, which will in turn allow to compare the real purchasing 
power between countries with different currencies, giving a broader and more global perspective on the idea of economic growth.

The global dynamics of economic growth are the main focus due to the global aspect of the Sustainable Development Goals. As important as individual economies are, the relationship between them is what defines the Sustainable Development Goals and presents the biggest problems. Taking global economic growth into account, that is, the total GDP growth of the world, it is possible to extrapolate that the total economy of the world is growing. However, many questions arise from this very simple analysis. Is that growth fair for everyone, or are there clear beneficiaries on the global scale? And is it sustainable for the developed world to pursue growth as it is doing?

These questions will be approached, trying to uncover some of the major problems with economic growth, in order to better understand the complex reality which holds many contradictions. Economic growth as a generally undefined concept is used all around the world by politicians and economists as a motivation and justification of multiple policies, defending the need to protect and maintain growth as one of the top priorities. This turns it into something really relevant to understand many of today's problems. The problem of economic growth is that it's simple and benign surface value masks problems with its distribution and sustainability throughout the world.

\section{The Myth of Economic Growth}

When most ordinary people think of economic growth they think of a complete positive outcome for society and an improvement for their lives in general. This sentiment of utter satisfaction with economic growth can, however, mislead the general public into ignoring factors regarding economic growth. These factors can be exploitation of another country in order to produce cheaper goods or the fact that the economic growth experienced does not correspond to changes in the society, for instance.

For example, the Democratic Republic of Congo has been experiencing a positive economic growth since 2002 , but nearly $88 \%$ of its working population is considered poor (under $3.20 \$$ a day PPP, HDR-UNDP) and its ranked $179^{\circ}$ in the Human Development index as of 2018 . There are multiple examples of "developing" countries that are in a similar situation to de DRC, where a very large economic growth does not correspond to an increase in living conditions.

Most Western based companies utilize these countries as production hubs due to cheap labour or set up deals to buy raw materials for technologic parts or such, without paying attention to the conditions of the living population. Such is the case of the DRC, where big tech companies buy minerals for very little, since the mine workers are brutally exploited by local warlords or cartels. Reports of child labour in cobalt mines and such in Congo are common, such as sweatshop workers in Bangladesh 
that are paid nearly half of what is considered to be the living minimum wage and work in barely humane conditions. (Kara, 2018) This allows for a big economic growth of the exporting country, and a stable but positive growth in the Western World, that is allowed to thrive as long as it continues to profit at the expenses of the so called Third world countries.

The role of the developed world must not continue as the exploiter. It needs to correct its behaviour and its companies must not harvest raw materials for profit with no regard for the human development. Economic growth has already translated into better human development in the developed world, and the constant search for more profit and higher growth is preventing developing countries from doing the same.

A myth that is commonly associated with the lack of improvement either in economic growth or in human development in the Third World is the lack of democracy. Many point to the regions small level of institutional democracy as a factor that harms the economy and consequently, the human development. However, many studies counter this popular belief. In fact, democracy does not fare well with economic growth at all. According to Erich Weede, the older a democracy is, the more its economic assets are surrendered to special interest groups, and this slows down the growth rate. Also, the larger the state, the slower the rate is. (Weede 1996, 217-219) Therefore, democracy is not a defining factor in good economic growth. In fact, it only slows the growth rate down.

As Mark Gradstein states, the most important factor to determine economic prosperity is the underlying economic structure in place. (Gradstein 2008, 1044-1063) This means that the developing world struggles not due to the lack of democracy or economic institutions but rather due to the lack of economic structure (and infrastructure to support it). The age of colonialism prevented (and continues to prevent) most of these countries from having said structure, negatively impacting their performance in the global market economy of the XXI century.

The underdevelopment of certain regions of the globe is therefore a systemic problem with historical roots. The exploitation that began with the colonial period of Europe through ownership of land and conquest has transformed into economic dominance and ownership through the economy. The numbers of economic growth that are frequently brought up do not show the reality of the relations between the multiple regions, since there are cases where higher economic growth is not necessarily better, for example when it does not change the living conditions for the better, or when it comes at the expense of another country.

\section{Endless Economic Growth \& the Environment}

The relation between economic growth and the environment is clear and possesses a massive contradiction that had been largely ignored until quite recently. In order to achieve economic growth, 
resources are necessary. However, resources are finite and are not easily replenished. So how do we articulate the idea of infinite economic growth with the reality of finite resources? We cannot. The system pushes the global economy to consume and produce goods at a spectacular pace, ever increasing, without ever taking into account the negative effect that it has on the environment.

It is imperative to understand the problem of this contradiction. It is impossible to maintain this system and its way of production, for its constant search for profit extracts more resources than those that can be replenished, and therefore cannot be maintained indefinitely. The economy is always linked to the environment and nature since it depends on them for their resources to produce, through industry and such, commodities that are then exchanged. However, the capitalist system doesn't take into account the environmental costs of production, since the ultimate goal in this system is to obtain profit. Profit is the only incentive in this system, so the environment suffers. The fashion industry is a prime example of this. A t-shirt can travel more than 30000 kilometres before it reaches the shelf, all in the name of profit. Raw materials are shipped to regions in the developing world where labour value and production costs are low, and then the good is shipped to the place where it is going to be sold. (Gaitho, 2018) This takes a huge toll on the environment due to increased pollution, and the problem of climate change cannot be ignored.

Multiple institutions have already flagged the problem of the environment and its solution is a transition into the so called "green economy", in which commodities are produced sustainably and with low carbon emissions and pollution. (Nordhaus 1977, 341-342) Many consider this to be a good option to prevent climate chaos, while solving many of the underlying problems of poverty and distribution of wealth and so on. However, this idea has some problems. Firstly, it is not profitable. All the investment in infrastructure and in the full restructuration of the economy turn green options not profitable, and therefore not desirable in the capitalist system. Even though some nations might have the funds to invest in green economy, many do not. And this is another problem with this green economy solution. There are economic differences between the regions that would prevent this change completely.

The problems with the green economy solution come only with the hegemonic economic system in the world and its contradictions, and until those are taken out of the equation, there will be no green economy.

\section{Decent Work \& Employment Growth}

As the world storms into another decade, job growth remains a concern all around the globe. The world appears to need more jobs to keep up with itself, either to deal with abnormally high unemployment rates or to keep the social structure in place while the economy recovers from yet another crisis. Work is pivotal in society as a whole and its problems and challenges mustn't be underrated. 
A recent study calculated that between 2010 and 2030, 734 million new jobs need to be created. This massive need for new jobs is due to manly trying to accommodate the new working-age population, that should expect an increase of $21 \%$. These changes in population make for a challenge in itself but achieving the goal of low unemployment rates makes for an even bigger one. The goal of a $4 \%$ unemployment rate or lower and $8 \%$ or lower for youths seems like an impossible task, even greater still when taking into consideration the SGD's consideration of decent work. (Poschen 2015, 1-2) Indeed, decent work for all turns the task of creating three quarters of a billion jobs into a nearly impossible task.

Furthermore, about $91 \%$ of these jobs will be needed in low or medium low-income countries. The problem with these economies is that they usually don't have the idea of decent work entrenched. Also, the lack of social policies can contribute to the lack of decent jobs. These less robust economies are the ones that need to absorb the biggest working age increase, and there are significant factors that can hinder this growth. (Poschen 2015, 1-2)

In order to better understand the difficulties in creating decent jobs for all in emerging economies (and also in economies in general), it becomes necessary to define decent work. In this paper I will use a broad definition inspired by the paper of David Bloom, Mathew McKenna and Klaus Prettner which in turn is inspired by the International Labour Organization. Decent work is, for the purpose of this paper, productive and financially decent work in conditions of freedom, equity, safety and human dignity (Bloom, McKenna \& Prettner 2018, 13-15). Also, when it comes to a macro analysis, decent work for all obviously implies the freedom of association and collective bargaining and the elimination of forced, compulsive and child labour. (Bloom, McKenna \& Prettner 2018, 13-15) There are multiple definition of decent work, some take into account statistics like the poverty line and so on, but this definition is sufficient to understand the concept of decent work.

So why is the creation of jobs such a concern? Especially in emerging economies? Well, there are multiple factors, but this paper focuses on two very important issues, the systemic problem of profit and the more modern problem of automation. It also explores the relation between these two threats for the SDG's decent work goals.

\section{The System \& Unemployment}

The general production and economy of the world is based on a capitalist system which is in turn ruled by profit. This system needs constant unemployment to create a pool of labour that, without proper legislation and social security, will drive wage costs down. Throughout the time when capitalism has been institutionalized, it has kept a long-term joblessness with punctual increases in short-term unemployment, due to the cyclical crisis and recessions that are part of the system. The system is ruled 
by the profits of the corporations, who actively search for an increase in their profits. These actions of maximizing profits bring consequences to the lives of the people who live and work under this system. (Wolff 2016, 60-62)

The consequences of the search for profit are very clear. Firstly, companies commonly shift their enterprises from high-wage countries to low-wage countries in order to maximize their profits. This leaves the high-wage countries with problems of unemployment and social security bills left behind by corporations. In turn, low-wage countries hardly gain anything, due to the nature of their relations with corporations, that must keep wages low again for the reason of profit. (Wolff 2016, 6869) Another problem of the profit search has been referenced above. It concerns the exploitation of the developing world, particularly in raw materials. Child labour, inhumane conditions and other problems are well documented; however, the moral responsibility of corporations speaks lower than profits.

Looking closer into the relationship between capitalism and unemployment, the American economist Richard Wolff has an interesting analysis. Employment under a capitalist system is decided mainly by the capitalists' desire to commence production, which in turn is decided by profit. (Wolff 2016, 60-62) In simple terms, if a certain product or service is profitable, capitalists will hire, and if it isn't profitable enough for them, the end result is unemployment. This is important when we take into consideration that there is a lot of work in our world. We need more teachers and health professionals, we need to maintain our infrastructure and build it in the developing world, and much more. We need to transition into green solutions for our economy and so on. The problem is that none of these activities are profitable. So, the main distinction between work and job is profit.

Another important study (Dwyer \& Wright 2019) concerns the polarization of jobs and the growth of low-wage jobs in the United States of America from 1980 until 2010. The study states that the services sector has experienced exponential growth, while manufacturing jobs have decreased. When it comes to polarization of the services sector, it confirms that is much more polarized than other sectors. (Dwyer \& Wright 2019, 63-65) This means that middle wage jobs are in decline, being replace mainly by low-wage jobs. The stagnation and decline of job quality are an obvious concern, since even though low-wage jobs are growing, the conditions of these are not necessarily improving. In order to try to balance the problem, this study recommends investment in infrastructure and care work (elderly care, children care, etc.) in order to maintain job growth and achieve a better working environment across the USA. (Dwyer \& Wright 2019, 70-73)

\section{The Problem of Automation}

As the world dives further into the $21^{\text {st }}$ century, the impact of technology in the dimension of work cannot simply be ignored. Humanity is experiencing a global boom in technological 
advancements, and with it rise questions regarding automation and the way of production across the globe.

As it stands, there aren't determinant studies (Frey \& Osborne 2017, 255-256) in this area that can accurately predict the path of automation and technology, due to the rapid acceleration on research and development of AI and other technologies. Even the use of potential technology cannot be fully understood by most studies.

However, technology has an impact on the distribution of work and jobs in general. For example, most manufacturing middle-wage jobs have continually been replaced by low-wage services jobs. (Frey \& Osborne 2017, 255) This means that increased automation doesn't necessarily translate to an easier time for the working people, but can do the exact opposite, causing them to lose their jobs and reallocating to a low service job. This problem has increased due to the decrease in computing prices and automation costs. The lower investments needed to automate make it easier for corporations to switch out their workers for automated machines in order to maximize profits, which derives from the systemic problems.

Recently, with surging talks about climate change and the environment, the so-called green economy might present itself as an opportunity to counter the systemic contradictions and to satisfy our job needs. In fact, when attempting to switch our entire mode of production into a new sustainable one, it presents a prime opportunity to insert unemployed people into new productive jobs that are sustainable. (Poschen 2015, 4)

There is evidence that the green economy can help with employment growth and with gains in income. These gains in income could also lead to increased equity and better social inclusion. However, these improvements depend on changes made to the current policies. A shift in investment and legislation is required in order to maximize the effects that the green economy can have in society. An important point to make is that most of these changes are not compatible with a system that demands the existence of profit and the need for constant unemployment. (Wolff 2016, 60-62)

\section{The SDGs}

The Sustainable Development Goals are a set of goals in many areas and sectors. This means that most of them are related in some way or another. Due to the nature of these goals that are interconnected, it is relevant to point out how these goals connect and what sectors are more important for achieving certain goals.

There are multiple sectors where the SDGs are at work. From ending poverty in all forms to the sustainable use of ecosystems, there are many areas and sectors that intersect and affect each other. 
However, these interactions aren't always beneficial. (Levy et al. 2015, 86-88) In a best-case scenario, all goals would work together and wouldn't contradict one another. This is not the case. For instance, achieving the goal of food security could put at risk agricultural sustainability advocated in another goal. Therefore, there are little to no priorities set when it comes to the different needs of regions or countries.

When it comes to the $8^{\text {th }} \mathrm{SDG}$, it stands as an intermediary between multiple goals. It reflects itself on the majority of the world economy, it concerns the largest parts of the mode of production, and it bridges the gap between efficient and sustainable resource use and the needs of the people. (Levy et al. 2015, 86-88) This middle ground is said to be one of the most essential parts for the success or failure of the SDG's, since it usually refers to infrastructure and the way of articulating the two needs. However, this vital role means that these SDGs are also the most challenging of all, even though they present the most opportunities to succeed. This dichotomy between challenge and opportunity is what makes this SDG so complex and so defining for society in general. Despite this positive but careful approach, the chapter that discusses the sectorial aspect of the SDGs has a critique to the $8^{\text {th }}$ SDG in particular. Since it affects most of the world economy, the radical decisions in this sector are taken by a small number of individuals, that can decide if the necessary changes happen. According to the authors, this shouldn't be the case. Instead, the decision making should be extended and discussed by the communities. (Levy et al. 2015, 87)

A different view on the SDGs has been developed by David Lempert. He sees the SDGs as more of a negative declaration of intent than actual goals to achieve. He states that the terms utilized across the SDGs do not use any legal terms, like development or sustainability. They lack definition, detail and even measurements. They do not set strategies to solve any issue and they don't define priorities according to different regions. (Lempert 2017, 121)

When it comes to the economic side of the SDGs, as is the case with number eight, the author states that the SDGs have no clear long-term solutions to poverty or economic problems regarding equity or equality. (Lempert 2017, 169) Also, it states that some goals regarding economy are meant as a neo-colonial way of "controlling the poor". (Lempert 2017, 156-157) That is, investing financial capital in certain regions in the developing world in order to push certain interests. These policies are highly criticised by the author, viewing the SDGs as way for the elites of the developed world to maintain dominance over the developing economies. Again, the problem of the elites is shown to harm the development of the SDGs, in a completely different scope.

The SDGs are not compatible with the logic of the economic system, engaging in a contradictory relationship where something that is not profitable (such as infrastructure or generally public enterprise) expects investments from a system ruled by profit. When it comes to the labour 
market, the same situation applies. The conditions generated by the system make it so that the SDGs are unachievable within that system.

\section{An Alternative?}

Capitalisms flaws are becoming apparent to a large portion of the world. The old economic powers of the West are showing that they do not have the will nor the resources to deal with its problems. This being said, is there an alternative?

Socialism is the traditional opponent of capitalism. The central planning and control of the economy, through direct ownership and regulations were popular in the $20^{\text {th }}$ century. Many countries embraced it as their preferred economic system. However, in the so-called West, traditional socialism does not rally the masses like it did in the past, and so, other alternatives are required.

The economist Richard Wolff presents a very interesting alternative to corporations and the decision power of the elites, that have been thought to harm the development of certain regions. His solution is to replace corporations with a small and restrictive circle of powerful individuals that make all the important decisions with of worker cooperatives, where the workers themselves own the corporation equally and make decisions democratically and collectively. (Wolff 2018, 1-5) He attributes the name of WSDE's, or worker self-directed enterprises. According to the author, this micro level change would have a huge impact. Due to its democratic nature, the relationship between environment or automation and work would change, and the power to decide on that would belong to all who work in a particular enterprise. (Wolff 2018, 1-5)

Another alternative, perhaps even complementary, is the public investment in infrastructure and care work. This would solidify our economies and our workplaces, fixing perhaps many of the problems that the SDGs attempt to solve, unsuccessfully.

\section{Conclusion}

This article proposed to analyse the $8^{\text {th }}$ Sustainable Development Goal when it comes to economic growth and decent work, using this content to critique the economic system and the conditions it creates in these sectors. It planned to find key points where the economic system and the SDGs themselves were to blame to the lack of impact of these global goals. The relationship between economic growth and real development was approached and also the case of the developing world and its challenges. The environment and resource efficiency were also covered, realising that they are incompatible with the system. When it comes to work, the systemic contradictions were exposed, and the problem of automation was taken into account. Finally, the SDGs were discussed in a broader sense, 
and a possible alternative was described. However, this alternative still needs developing and a considerable study to be clearly viable.

The SDGs flaws show that their usefulness is limited at best, and without proper goals and strategies no action will be sufficient to tackle all of Humanity's problems, including climate change, social equity and wealth distribution. 


\section{Bibliography}

Bloom, David E., Mathew McKenna, and Klaus Prettner. 2018. "Demography, Unemployment, Automation, And Digitalization: Implications For The Creation Of (Decent) Jobs, 2010-2030". NBER Working Paper, 24835, July 2018.

Dwyer, Rachel E., and Erik Olin Wright. 2019. "Low-Wage Job Growth, Polarization, And The Limits And Opportunities Of The Service Economy". The Russell Sage Foundation Journal Of The Social Sciences 5 (4): 56-76.

Frey, Carl Benedikt, and Michael A. Osborne. 2017. "The Future Of Employment: How Susceptible Are Jobs To Computerisation?". Technological Forecasting \& Social Change 114: 254-280.

Gaitho, Maryanne. "How Far Do Your Clothes Travel to Reach You?" Fabric of the world, April 3, 2018. http://www.fabricoftheworld.com/fashion-on-a-toxic-trip-just-how-far-do-your-clothes-travelto-reach-you/.

Gradstein, Mark. 2008. "Institutional Traps And Economic Growth". International Economic Review 49 (3): 1043-1066.

Kara, Siddharth. "Is Your Phone Tainted by the Misery of 35,000 Children in Congo's Mines? | Siddharth Kara." The Guardian. Guardian News and Media, October 12, 2018. https://www.theguardian.com/global-development/2018/oct/12/phone-misery-children-congo-cobaltmines-drc.

Lempert, David. 2017. "Testing The Global Community'S Sustainable Development Goals (Sdgs) Against Professional Standards And International Law". Consilience, 18: 111-175.

Levy, Caren, Christopher Yap, Colin Marx, David Hudson, Elaine Unterhalter, Georgina Mace, and Jeff Waage et al. 2015. "Governing Sustainable Development Goals: Interactions, Infrastructures, And Institutions". In Thinking Beyond Sectors For Sustainable Development, 1st ed. Ubiquity Press.

Nordhaus, W. D., 1977. Economic Growth and Climate: The Carbon Dioxide Problem. The American Economic Review, 67(1), pp.341-346.

Poschen, Peter. 2017. Decent Work, Green Jobs \& Sustainable Economy. NY: Routledge.

Schumpeter, Joseph A. 1947. "Theoretical Problems: Theoretical Problems Of Economic Growth". The Journal Of Economic History 7: 1-9.

Weede, Erich. 1996. "Legitimacy, Democracy, And Comparative Economic Growth Reconsidered". European Sociological Review 12 (3): 217-225.

Wolff, Richard D. 2016. Capitalism's Crisis Deepens. Chicago: Haymarket Books. 
Wolff, Richard D. 2018. "Democracy And The (Ir)Responsibility Of Economics". Forum For Social Economics 47 (2): 220-223. 